\title{
High RAD54B expression: an independent predictor of postoperative distant recurrence in colorectal cancer patients
}

\author{
Yuzo Nagai ${ }^{1}$, Yoko Yamamoto ${ }^{1}$, Takaaki Yasuhara ${ }^{2}$, Keisuke Hata ${ }^{1}$, Takeshi \\ Nishikawa ${ }^{1}$, Toshiaki Tanaka ${ }^{1}$, Junichiro Tanaka ${ }^{1}$, Tomomichi Kiyomatsu ${ }^{1}$, \\ Kazushige Kawai ${ }^{1}$, Hiroaki Nozawa ${ }^{1}$, Shinsuke Kazama ${ }^{1}$, Hironori Yamaguchi ${ }^{1}$, \\ Soichiro Ishihara1, Eiji Sunami ${ }^{1}$, Takeharu Yamanaka ${ }^{3}$, Kiyoshi Miyagawa ${ }^{2}$ and \\ Toshiaki Watanabe ${ }^{1}$ \\ ${ }^{1}$ Department of Surgical Oncology, Faculty of Medicine, The University of Tokyo, Hongo, Bunkyo-ku, Tokyo, Japan \\ ${ }^{2}$ Laboratory of Molecular Radiology, Center for Disease Biology and Integrative Medicine, Graduate School of Medicine, The \\ University of Tokyo, Hongo, Bunkyo-ku, Tokyo, Japan \\ ${ }^{3}$ Department of Biostatistics, Graduate School of Medicine, Yokohama City University, Suehiro-cho, Tsurumi-ku, Yokohama, \\ Kanagawa, Japan \\ Correspondence to: Toshiaki Watanabe, email: toshwatanabe@yahoo.co.jp \\ Keywords: RAD54B, colorectal cancer, homologous recombination, prognosis, distant recurrence \\ Received: April 21, $2015 \quad$ Accepted: May 09, $2015 \quad$ Published: May 20, 2015
}

This is an open-access article distributed under the terms of the Creative Commons Attribution License, which permits unrestricted use, distribution, and reproduction in any medium, provided the original author and source are credited.

\section{ABSTRACT}

We recently reported a specific mechanism that RAD54B, an important factor in homologous recombination, promotes genomic instability via the degradation of p53 protein in vitro. However, clinical significance of RAD54B in colorectal cancer (CRC) remains unclear. Thus we analyzed RAD54B gene expression in CRC patients. Using the training set $(n=123)$, the optimal cut-off value for stratification was determined, and validated in another cohort $(n=89)$. Kaplan-Meier plots showed that distant recurrence free survival was significantly lesser in high RAD54B expression group compared with that of low expression group in both training $(P=0.0013)$ and validation $(P=\mathbf{0 . 0 2 4})$ set. Multivariate analysis using Cox proportional-hazards model showed that high RAD54B expression was an independent predictor in both training (hazard ratio, 4.31; 95\% CI, 1.53-13.1; $P=0.0060$ ) and validation (hazard ratio, $3.63 ; 95 \% C I, 1.23-10.7 ; P=0.021$ ) set. In addition, a negative significant correlation between RAD54B and CDKN1A, a target gene of p53, was partially confirmed, suggesting that RAD54B functions via the degradation of p53 protein even in clinical samples. This study first demonstrated RAD54B expression has potential to serve as a novel prognostic biomarker, particularly for distant recurrence in CRC patients.

\section{INTRODUCTION}

Despite the recent progress in the therapeutic modalities, colorectal cancer (CRC) is a serious public health issue worldwide owing to its high incidence and cancer-related mortality [1]. In addition to TNM staging system, several biomarkers are currently applied to practical use for CRC patients. For example, UGT1A1 genetic polymorphism is associated with CPT-11 toxicity [2]. KRAS/NRAS mutations status predicts response to anti-EGFR antibody therapy [3, 4]. CRC with microsatellite instability has a better prognosis compared to CRC with intact mismatch repair [5]. Such biomarkers have improved clinical outcomes in CRC, however, the number of biomarkers still remains insufficient, and more studies exploring new biomarkers are required to establish further personalized therapeutic strategy.

Human $R A D 54 B$ was first identified in 1999 as a homolog of RAD54. RAD54B belongs to SNF2/SWI2 superfamily, and biochemical studies have shown that RAD54B is involved in the homologous recombination (HR) [6-9]. HR is one of the most important DNA doublestrand break repair pathway. It is generally accepted that imbalanced regulation of the HR system is associated with genomic instability, resulting in carcinogenesis and malignant tumor development [10-12]. 
Recently, our group found another mechanism different from the HR repair pathway in multiple cell line experiments, including the HCT116 colon cancer cell line. RAD54B is associated with cell cycle control and functions as a scaffold for p53 degradation through its direct interaction with the MDM2-MDMX ubiquitinligase complex, and constitutive upregulation of RAD54B activity promotes genomic instability [13]. Although one study concerning the effectiveness of capecitabine and concurrent radiation therapy for glioblastoma analyzed the expression profiles of eight genes including $R A D 54 B$ and reported that high $R A D 54 B$ expression was associated with a poor outcome [14], the clinical significance of $R A D 54 B$ expression remains unknown particularly in CRC.

Therefore, we examined $R A D 54 B$ expression in surgically resected CRC tissues by real-time PCR method and analyzed the correlation with various clinicopathological factors and patient's prognosis. In addition to $R A D 54 B$, we also analyzed $R A D 51$ expression in the same cohort because RAD51 is another important factor involved in HR process [15-18] and several studies reported that RAD51 protein overexpression is associated with poor prognosis in various cancers [19-24]. Moreover, we measured $C D K N 1 A$ (p21/WAF1) expression, a target gene of $\mathrm{p} 53$, and analyzed the association between $R A D 54 B$ and $C D K N 1 A$ expression to investigate the biological role of $R A D 54 B$ in clinical samples. From a clinical perspective, this is the first study demonstrating the utility of $R A D 54 B$ as a prognostic biomarker in CRC patients.

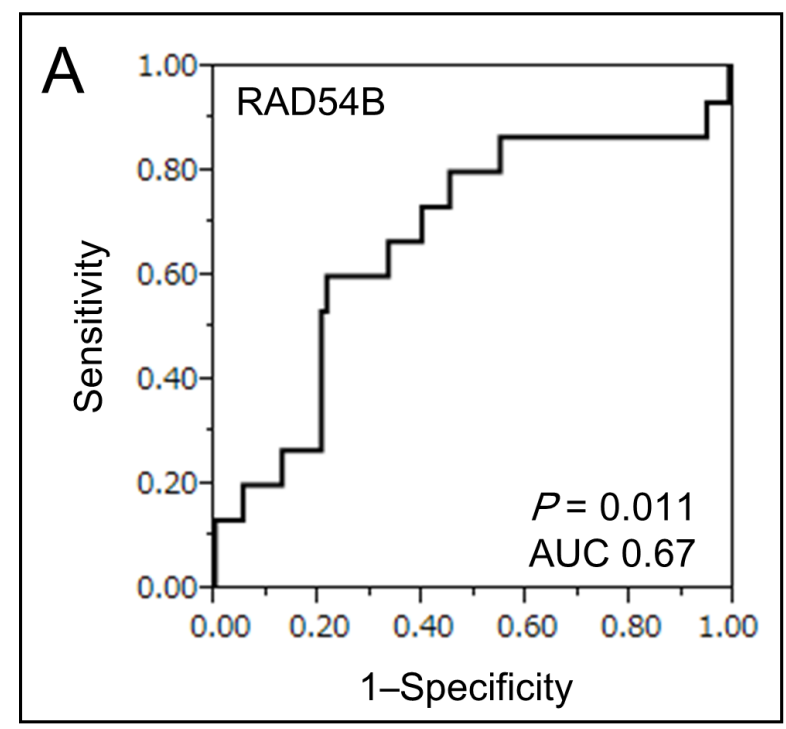

\section{RESULTS}

\section{$R A D 54 B$ expression was elevated in most CRC tissues}

We first analyzed $R A D 54 B$ and $R A D 51$ expression in the training set $(n=123)$. Gene expression of $R A D 54 B$, RAD51 were quantified by real-time PCR as described in the Materials and Methods section. Table 1 shows the summary of $R A D 54 B$ and $R A D 51$ expression values in the training set. The median (inter-quartile range) $R A D 54 B$ expression value was $2.60(2.50-3.99)$, and $R A D 54 B$ expression values were higher than 1.00 in 116 of the 123 samples $(94.3 \%)$, indicating that $R A D 54 B$ expression was elevated in most CRC tissues compared with corresponding normal mucosa. In contrast, RAD5I expression value $[1.15(0.80-1.56)]$ was not as elevated as $R A D 54 B$. The number of samples with values higher than 1.00 was 74 of the 123 samples $(60.2 \%)$, which was significantly smaller than that of $R A D 54 B(P=0.0008)$.

\section{$R A D 54 B$ and $R A D 51$ expression values and clinicopathological factors in the training set}

We next analyzed the relationship between $R A D 54 B$ or $R A D 51$ expression and clinicopathological features in the training set. As shown in Table 2, no statistically significant correlations were found between $R A D 54 B$ expression values and clinicopathological factors, such as

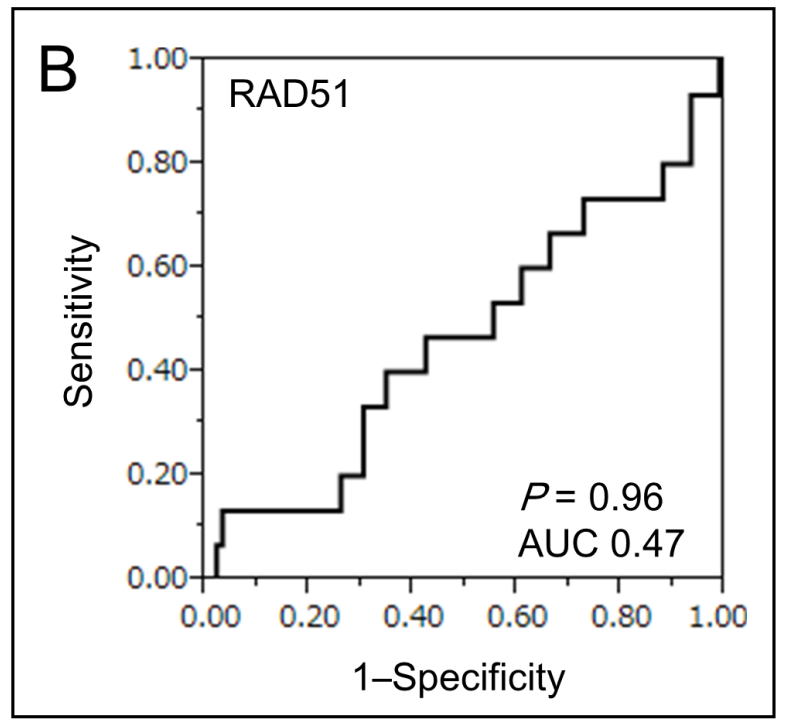

Figure 1: ROC curve analysis of $\boldsymbol{R A D 5 4 B}$ and $\boldsymbol{R} \boldsymbol{A D 5 1}$ expression. A. ROC curve analysis using $R A D 54 B$ expression values for distinguishing patients developing distant recurrence in the training set. The estimated optimal cut-off value of $R A D 54 B$ expression was 3.63 (AUC $0.67, P=0.011$ ). B. ROC curve analysis using $R A D 51$ expression values for distinguishing patients developing distant recurrence in the training set (AUC 0.47, $P=0.96$ ). 
Table 1: $R A D 54 B$ and $R A D 51$ expression values in the training set $(n=123)$.

\begin{tabular}{|c|c|c|c|c|c|}
\hline \multicolumn{1}{|c|}{ Category } & No. & RAD54B value & No. & \multicolumn{2}{c|}{$R A D 51$ value } \\
\hline All patients & & $2.60(2.50-3.99)$ & \multicolumn{2}{c|}{$1.15(0.80-1.56)$} & \\
\hline Expression value $<1.00$ & $7(5.69 \%)$ & & $49(39.8 \%)$ & 0.0008 \\
\hline Expression value $\geq 1.00$ & $116(94.3 \%)$ & & $74(60.2 \%)$ & & \\
\hline
\end{tabular}

Table 2: Clinicopathological factors and $R A D 54 B$ and $R A D 51$ expression values in the training set $(\mathrm{n}=123)$.

\begin{tabular}{|c|c|c|c|c|c|c|}
\hline Category & & No $(\%)$ & $R A D 54 B$ value & $P$ value & $R A D 51$ value & $P$ value \\
\hline \multirow[t]{2}{*}{ Sex } & Male & $65(52.8)$ & $2.46(1.52-3.60)$ & 0.11 & $1.02(0.71-1.50)$ & 0.65 \\
\hline & Female & $58(47.2)$ & $2.78(2.16-4.16)$ & & $1.23(0.84-1.62)$ & \\
\hline \multirow[t]{2}{*}{ Age } & $<65$ & $56(45.5)$ & $2.72(1.97-4.19)$ & 0.91 & $1.14(0.81-1.56)$ & 0.97 \\
\hline & $\geq 65$ & $67(54.5)$ & $2.50(2.10-3.65)$ & & $1.15(0.77-1.57)$ & \\
\hline \multirow[t]{2}{*}{ Tumor location } & Colon & $96(78.0)$ & $2.69(2.05-4.22)$ & 0.28 & $1.19(0.79-1.58)$ & 0.34 \\
\hline & Rectum & $27(22.0)$ & $2.42(1.97-3.40)$ & & $1.02(0.80-1.48)$ & \\
\hline \multirow[t]{2}{*}{ Tumor size $(\mathrm{mm})$} & $<50$ & $66(53.7)$ & $2.48(2.05-3.24)$ & 0.12 & $1.17(0.80-1.53)$ & 0.93 \\
\hline & $\geq 50$ & $57(46.3)$ & $2.88(1.98-4.73)$ & & $1.05(0.78-1.58)$ & \\
\hline \multirow[t]{3}{*}{ Cell differentiation } & WD & $57(46.3)$ & $2.48(1.98-3.33)$ & 0.42 & $1.20(0.79-1.56)$ & 0.68 \\
\hline & MD & $62(50.4)$ & $2.62(2.08-4.33)$ & & $1.11(0.78-1.57)$ & \\
\hline & $\mathrm{PD}$ & $4(3.3)$ & $4.47(1.97-5.40)$ & & $1.50(0.82-2.74)$ & \\
\hline \multirow[t]{2}{*}{ Lymphatic invasion } & Positive & $47(38.2)$ & $2.66(1.57-4.57)$ & 0.92 & $1.35(0.97-1.79)$ & 0.027 \\
\hline & Negative & $76(61.8)$ & $2.56(2.14-3.69)$ & & $1.01(0.79-1.48)$ & \\
\hline \multirow[t]{2}{*}{ Venous invasion } & Positive & $27(22.0)$ & $2.58(2.00-4.12)$ & 0.94 & $1.13(0.80-1.57)$ & 0.97 \\
\hline & Negative & $96(78.0)$ & $2.56(2.05-3.41)$ & & $1.18(0.79-1.53)$ & \\
\hline \multirow[t]{2}{*}{ Preoperative CEA } & $<5.0$ & $61(49.6)$ & $2.44(1.87-4.11)$ & 0.67 & $1.17(0.80-1.56)$ & 0.28 \\
\hline & $\geq 5.0$ & $61(49.6)$ & $2.72(2.10-3.82)$ & & $1.14(0.79-1.56)$ & \\
\hline \multirow[t]{2}{*}{ Preoperative CA19-9 } & $<37$ & $99(80.5)$ & $2.56(1.98-3.78)$ & 0.59 & $1.10(0.80-1.56)$ & 0.26 \\
\hline & $\geq 37$ & $23(18.7)$ & $2.97(2.10-4.54)$ & & $1.35(0.69-1.93)$ & \\
\hline \multirow[t]{4}{*}{ Tumor stage (UICC) } & $\mathrm{I}$ & $13(10.6)$ & $2.58(2.13-3.04)$ & 0.20 & $1.09(0.76-1.38)$ & 0.078 \\
\hline & II & $51(41.5)$ & $2.72(2.23-4.45)$ & & $1.18(0.80-1.56)$ & \\
\hline & III & $44(35.8)$ & $2.42(1.43-3.59)$ & & $1.02(0.73-1.53)$ & \\
\hline & IV & $15(12.2)$ & $2.98(2.11-5.26)$ & & $1.56(1.13-2.67)$ & \\
\hline \multirow[t]{4}{*}{ T stage } & $\mathrm{T} 1$ & $5(4.1)$ & $2.21(1.05-5.31)$ & 0.16 & $0.68(0.36-9.42)$ & 0.51 \\
\hline & $\mathrm{T} 2$ & $18(14.6)$ & $2.76(2.08-3.03)$ & & $1.09(0.87-1.40)$ & \\
\hline & $\mathrm{T} 3$ & $60(48.8)$ & $2.44(1.62-3.94)$ & & $1.13(0.78-1.53)$ & \\
\hline & $\mathrm{T} 4$ & $40(32.5)$ & $2.87(2.18-5.32)$ & & $1.28(0.81-1.79)$ & \\
\hline \multirow[t]{3}{*}{$\mathrm{N}$ stage } & No & $67(54.5)$ & $2.72(2.21-3.87)$ & 0.23 & $1.15(0.80-1.51)$ & 0.38 \\
\hline & $\mathrm{N} 1$ & $47(38.2)$ & $2.46(1.53-3.42)$ & & $1.04(0.78-2.28)$ & \\
\hline & $\mathrm{N} 2$ & $9(7.3)$ & $4.54(1.77-6.00)$ & & $1.39(1.11-1.76)$ & \\
\hline \multirow{2}{*}{$\begin{array}{l}\text { Distant Recurrence } \\
\text { in Stage I -III }\end{array}$} & Yes & $15(12.2)$ & $3.87(2.55-4.88)$ & 0.031 & $1.16(0.81-1.79)$ & 0.69 \\
\hline & No & $93(75.6)$ & $2.46(1.92-3.24)$ & & $1.07(0.78-1.52)$ & \\
\hline
\end{tabular}

$\mathrm{WD}=$ well differentiated; $\mathrm{MD}=$ moderately differentiated; $\mathrm{PD}=$ poorly differentiated.

sex, age, tumor location, tumor size, cell differentiation, lymphatic invasion, venous invasion, and preoperative CEA and CA19-9 levels. Similarly, no significant correlations were detected between $R A D 54 B$ expression values and UICC stage $(P=0.20)$, T stage $(P=0.16)$, and $\mathrm{N}$ stage $(P=0.23)$. Likewise, there was no association between $R A D 51$ expression values and clinicopathological factors including UICC stage $(P=0.078)$, T stage $(P$ $=0.51)$, and $\mathrm{N}$ stage $(P=0.38)$, except that $R A D 51$ expression values in lymphatic invasion-positive patients were significantly higher than those in negative patients $(P=0.027)$.

\section{$R A D 54 B$ and $R A D 51$ expression and patient prognosis in the training set}

Among the 108 stage I-III CRC patients (excluding stage IV patients) in the training set, 15 patients developed distant recurrence during the median follow-up period of 50.7 (40.9-59.9) months (Table 2). RAD54B expression values in patients developing distant recurrence were significantly higher than those in patients without distant recurrence $[3.87$ (2.55-4.88) vs. 2.46 (1.92-3.24); $P=$ 0.031 ; Table 2], suggesting that high $R A D 54 B$ expression 
Table 3: Comparison of clinicopathological factors between $R A D 54 B$ high and low groups.

\begin{tabular}{|c|c|c|c|c|c|c|c|}
\hline & & \multirow{2}{*}{\multicolumn{2}{|c|}{$\begin{array}{c}\text { Training set }(\mathbf{n}=\mathbf{1 0 8}) \\
R A D 54 B \text { Group }\end{array}$}} & \multirow{2}{*}{\multicolumn{4}{|c|}{$\begin{array}{c}\text { Validation set }(\mathbf{n}=\mathbf{7 1}) \\
R A D 54 B \text { Group }\end{array}$}} \\
\hline & & & & & & & \\
\hline & & Low $(n=79)$ & $\operatorname{High}(\mathrm{n}=29)$ & & Low $(\mathrm{n}=53)$ & $\operatorname{High}(n=18)$ & \\
\hline \multicolumn{2}{|l|}{ Category } & No (\%) & No $(\%)$ & $P$ value & No $(\%)$ & No $(\%)$ & $P$ value \\
\hline \multirow[t]{2}{*}{ Sex } & Male & $44(55.7)$ & $13(44.8)$ & 0.32 & $33(62.3)$ & $10(55.6)$ & 0.61 \\
\hline & Female & $35(44.3)$ & $16(55.2)$ & & $20(37.7)$ & $8(44.4)$ & \\
\hline \multirow[t]{2}{*}{ Age } & $<65$ & $32(40.5)$ & $14(48.3)$ & 0.47 & $22(41.5)$ & $4(22.2)$ & 0.14 \\
\hline & $\geq 65$ & $47(59.5)$ & $15(51.7)$ & & $31(58.5)$ & $14(77.8)$ & \\
\hline \multirow[t]{2}{*}{ Tumor location } & Colon & $58(73.4)$ & $26(89.7)$ & 0.072 & $37(69.8)$ & $12(66.7)$ & 0.80 \\
\hline & Rectum & $21(26.6)$ & $3(10.3)$ & & $16(30.2)$ & $6(33.3)$ & \\
\hline \multirow[t]{2}{*}{ Tumor size $(\mathrm{mm})$} & $<50$ & $48(60.8)$ & $14(48.3)$ & 0.24 & $28(52.8)$ & $8(44.4)$ & 0.54 \\
\hline & $\geq 50$ & $31(39.2)$ & $15(51.7)$ & & $25(47.2)$ & $10(55.6)$ & \\
\hline \multirow[t]{2}{*}{ Cell differentiation } & WD & $41(51.9)$ & $12(41.4)$ & 0.33 & $26(49.1)$ & $6(33.3)$ & 0.25 \\
\hline & $\mathrm{MD} / \mathrm{PD}$ & $38(48.1)$ & $17(58.6)$ & & $27(50.9)$ & $12(66.7)$ & \\
\hline \multirow[t]{2}{*}{ Lymphatic invasion } & Positive & $24(30.4)$ & $12(41.4)$ & 0.28 & $19(35.8)$ & $3(16.7)$ & 0.13 \\
\hline & Negative & $55(69.6)$ & $17(58.6)$ & & $34(64.2)$ & $15(83.3)$ & \\
\hline \multirow[t]{2}{*}{ Venous invasion } & Positive & $59(74.7)$ & $5(17.2)$ & 0.38 & $37(69.8)$ & $12(66.7)$ & 0.80 \\
\hline & Negative & $20(25.3)$ & $24(82.8)$ & & $16(30.2)$ & $6(33.3)$ & \\
\hline \multirow[t]{2}{*}{ Preoperative CEA } & $<5.0$ & $41(51.9)$ & $16(55.2)$ & 0.76 & $29(54.7)$ & $7(38.9)$ & 0.25 \\
\hline & $\geq 5.0$ & $38(48.1)$ & $13(44.8)$ & & $24(45.3)$ & $11(61.1)$ & \\
\hline \multirow[t]{2}{*}{ Preoperative CA19-9 } & $<37$ & $69(87.3)$ & $24(82.8)$ & 0.88 & $43(81.1)$ & $15(83.3)$ & 0.83 \\
\hline & $\geq 37$ & $10(12.3)$ & $5(17.2)$ & & $10(18.9)$ & $3(16.7)$ & \\
\hline \multirow[t]{3}{*}{ Tumor stage (UICC) } & $\mathrm{I}$ & $12(15.2)$ & $1(3.4)$ & 0.17 & $7(13.2)$ & $3(16.7)$ & 0.88 \\
\hline & II & $34(43.0)$ & $17(58.6)$ & & $19(35.8)$ & $7(38.9)$ & \\
\hline & III & $33(41.8)$ & $11(37.9)$ & & $27(50.9)$ & $8(44.4)$ & \\
\hline \multirow[t]{2}{*}{ T stage } & T1-2 & $21(26.6)$ & $2(6.9)$ & 0.027 & $9(17.0)$ & $4(22.2)$ & 0.62 \\
\hline & T3-4 & $58(73.4)$ & $27(93.1)$ & & $44(83.0)$ & $14(77.8)$ & \\
\hline \multirow[t]{2}{*}{$\mathrm{N}$ stage } & No & $46(58.2)$ & $18(62.1)$ & 0.72 & $26(49.1)$ & $11(61.1)$ & 0.38 \\
\hline & $\mathrm{N} 1-2$ & $33(41.8)$ & $11(37.9)$ & & $27(50.9)$ & $7(38.9)$ & \\
\hline \multirow[t]{2}{*}{ Adjuvant chemotherapy } & Yes & $24(30.4)$ & $9(31.0)$ & 0.95 & $23(43.4)$ & $6(33.3)$ & 0.45 \\
\hline & No & $55(69.6)$ & $20(69.0)$ & & $30(56.6)$ & $12(66.7)$ & \\
\hline \multirow[t]{2}{*}{ Distant Recurrence } & Yes & $6(7.6)$ & $9(31.0)$ & 0.0018 & $7(13.2)$ & $7(38.9)$ & 0.024 \\
\hline & No & $73(92.4)$ & $20(69.0)$ & & $46(86.8)$ & $11(61.1)$ & \\
\hline
\end{tabular}

$\mathrm{WD}=$ well differentiated; $\mathrm{MD}=$ moderately differentiated; $\mathrm{PD}=$ poorly differentiated.
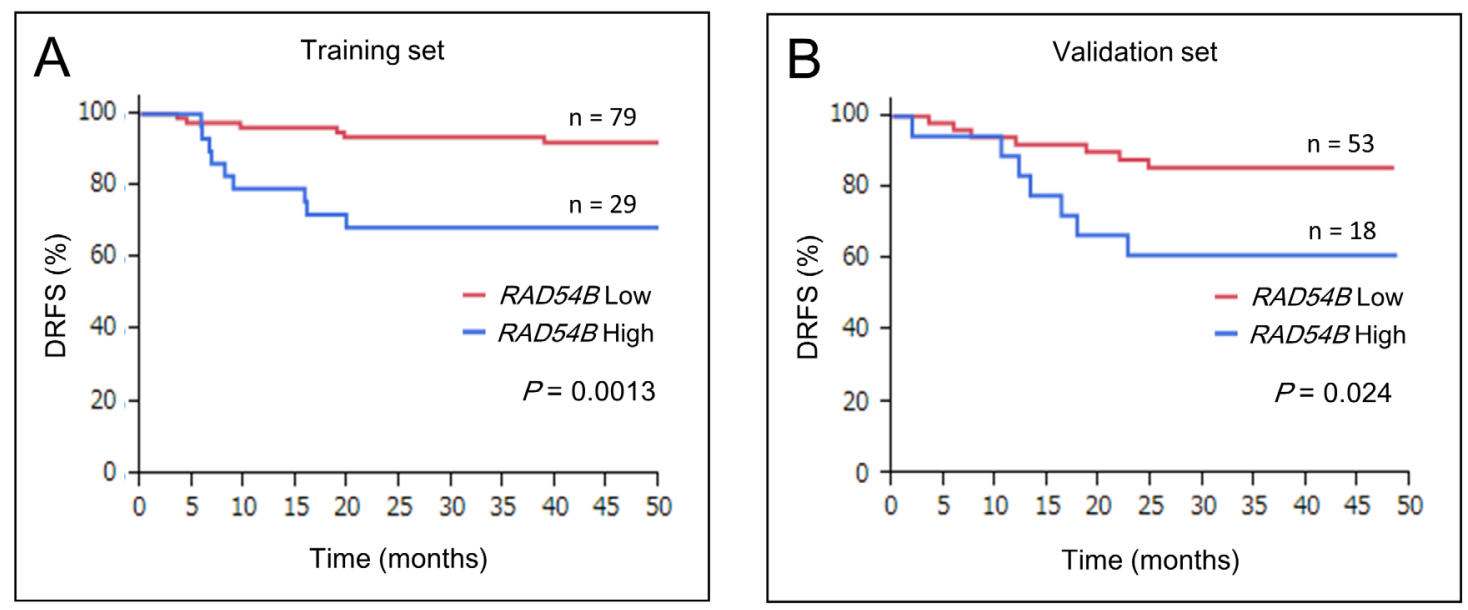

Figure 2: DRFS of $\boldsymbol{R} \boldsymbol{A D 5 4 B}$ high and low groups. A. Kaplan-Meier survival analyses of 108 stage I-III CRC patients in the training set revealed that the $R A D 54 B$ high group had inferior DRFS compared with the low group $(P=0.0013)$. B. Kaplan-Meier survival analyses of 71 stage I-III CRC patients in the validation set revealed that the RAD54B high group had inferior DRFS compared with the low group $(P=0.024)$. 
Table 4: Univariate and multivariate analysis of the factors associated with DRFS.

\begin{tabular}{|c|c|c|c|c|}
\hline Training set & $\begin{array}{c}\text { Univariate analysis } \\
P \text { value }\end{array}$ & HR & $\begin{array}{c}\text { Multivariate analysis } \\
95 \% \mathrm{CI}\end{array}$ & $P$ value \\
\hline$R A D 54 B$ (High vs Low group) & 0.0013 & 4.31 & 1.53 to 13.1 & 0.0060 \\
\hline T stage (T1-2 vs T3-4) & 0.14 & 2.96 & 0.57 to 54.4 & 0.23 \\
\hline $\mathrm{N}$ stage (N0 vs N1-2) & 0.14 & 2.44 & 0.88 to 7.23 & 0.088 \\
\hline Cell differentiation (WD vs MD/PD) & 0.073 & - & - & - \\
\hline Lymphatic invasion (positive vs negative) & 0.090 & - & - & - \\
\hline Venous invasion (positive vs negative) & 0.33 & - & - & - \\
\hline Preoperative CEA $(<5.0$ vs $\geq 5.0)$ & 0.51 & - & - & - \\
\hline Preoperative CA19-9 (<37 vs $\geq 37)$ & 0.89 & - & - & - \\
\hline Age $(<65$ vs $\geq 65)$ & 0.37 & - & - & - \\
\hline Location (Colon vs Rectum) & 0.94 & - & - & - \\
\hline Sex (Male vs Female) & 0.34 & - & - & - \\
\hline Tumor size $(\mathrm{mm})(<50$ vs $\geq 50)$ & 0.49 & - & - & - \\
\hline Validation set & $\begin{array}{c}\text { Univariate analysis } \\
P \text { value }\end{array}$ & $\mathrm{HR}$ & $\begin{array}{c}\text { Multivariate analysis } \\
95 \% \mathrm{CI}\end{array}$ & $P$ value \\
\hline$R A D 54 B$ (High vs Low group) & 0.024 & 3.627 & 1.23 to 10.7 & 0.021 \\
\hline T stage (T1-2 vs T3-4) & 0.18 & 3.432 & 0.66 to 63.1 & 0.17 \\
\hline $\mathrm{N}$ stage (N0 vs N1-2) & 0.13 & 2.182 & 0.74 to 7.21 & 0.16 \\
\hline Cell differentiation (WD vs MD/PD) & 0.34 & - & - & - \\
\hline Lymphatic invasion (positive vs negative) & 0.54 & - & - & - \\
\hline Venous invasion (positive vs negative) & 0.094 & - & - & - \\
\hline Preoperative CEA $(<5.0$ vs $\geq 5.0)$ & 0.073 & - & - & - \\
\hline Preoperative CA19-9 $(<37$ vs $\geq 37)$ & 0.19 & - & - & - \\
\hline Age $(<65$ vs $\geq 65)$ & 0.41 & - & - & - \\
\hline Location (Colon vs Rectum) & 0.74 & - & - & - \\
\hline Sex (Male vs Female) & 0.71 & - & - & - \\
\hline Tumor size $(\mathrm{mm})(<50$ vs $\geq 50)$ & 0.84 & - & - & - \\
\hline
\end{tabular}

$\mathrm{WD}=$ well differentiated; $\mathrm{MD}=$ moderately differentiated; $\mathrm{PD}=$ poorly differentiated; $\mathrm{HR}=$ hazard ratio;

$\mathrm{CI}=$ confidence interval.

is associated with inferior prognostic outcome, specifically by causing postoperative distant metastasis. In contrast, RAD51 expression values were not significantly different between patients with and without distant recurrence [1.16 (0.81-1.79) vs. $1.07(0.78-1.52) ; P=0.69$; Table 2]. According to these findings, we selected DRFS as the primary endpoint to further evaluate the prognostic ability of $R A D 54 B$.

\section{Clinicopathological features of $R A D 54 B$ high and low groups in the training set}

To evaluate the prognostic ability of $R A D 54 B$ on DRFS, the optimal cut-off value of $R A D 54 B$ expression for segregating DRFS was determined by receiver operating characteristic curve (ROC) analysis (Figure 1A). With the optimal cut-off value of 3.63, 108 stage IIII CRC patients in the training set were divided into two groups: low group $(n=79)$ and high group $(n=29)$. In contrast, we could not determine the optimal cut-off value of RAD51 expression in the training set due to a low area under curve (AUC) score (Figure 1B).

Table 3 demonstrates a comparison of clinicopathological features of the $R A D 54 B$ high and low groups in the training set $(n=108)$. Although the RAD $54 B$ high group had more advanced $\mathrm{T}$ stage $(P=0.027)$, factors including sex, age, tumor location, tumor size, cell differentiation, lymphatic invasion, venous invasion, preoperative tumor markers, UICC stage, and $\mathrm{N}$ stage were similar in both groups. Twenty-four patients (30.4\%) in the $R A D 54 B$ low group and nine patients $(31.0 \%)$ in the high group received postoperative adjuvant chemotherapy consisting of 5-fluorouracil (5-FU)-based regimens ( $P=$ $0.95)$. During the median follow-up period of 50.7 (40.9$59.9)$ months, six patients $(7.6 \%)$ in the RAD54B low group $(n=79)$ and nine patients $(31.0 \%)$ in the high group $(n=29)$ developed distant recurrence $(P=0.0018)$.

\section{High $R A D 54 B$ expression is an independent risk factor for distant recurrence}

Kaplan-Meier survival analyses of 108 stage I-III CRC patients in the training set revealed that the RAD $54 B$ high group had inferior DRFS compared with the low group (estimated 3-year DRFS was $93.5 \%$ in the low group and $68.5 \%$ in the high group; $P=0.0013$; Figure $2 \mathrm{~A})$. Multivariate analysis using the Cox proportionalhazards model showed that high $R A D 54 B$ expression was the only independent prognostic factor associated with DRFS in the training set (hazard ratio, 4.31; 95\% CI, $1.53-13.1 ; P=0.0060$; Table 4). 


\section{RAD54B expression in the validation set}

Next, the $R A D 54 B$ expression cut-off value of 3.63 determined in the training set was applied to the independent cohort of 89 CRC patients for validation. Seventy-one stage I-III CRC patients (excluding stage IV patients) in the validation set were stratified into the $R A D 54 B$ low $(n=53)$ and high $(n=18)$ expression groups. Table 3 shows that clinicopathological factors including UICC stage, $\mathrm{T}$ stage, and $\mathrm{N}$ stage were not significantly different in the two groups. During the median follow-up period of 37.0 (28.5-46.0) months, seven patients $(13.2 \%)$ in the $R A D 54 B$ low group $(n=$ $53)$ and seven patients $(38.9 \%)$ in the high group $(n=$ 18 ) developed distant recurrence (Table 3, $P=0.024$ ). Kaplan-Meier survival analyses revealed that the RAD $54 B$ high group had inferior DRFS compared with the low group with (estimated 3-year DRFS was $85.7 \%$ in the low group and $61.1 \%$ in the high group; $P=0.024$; Figure 2B). Multivariate analysis using the Cox proportionalhazards model showed that high $R A D 54 B$ expression was an independent prognostic factor associated with DRFS even in the validation set (hazard ratio, 3.63; 95\% CI, $1.23-10.7 ; P=0.021$; Table 4).

\section{$R A D 54 B$ expression is inversely correlated with $C D K N 1 A$ expression}

We next studied the relationship between $R A D 54 B$ and $\mathrm{p} 53$ functions in clinical CRC samples. Because p53 activates $C D K N 1 A$ gene transcription and its expression reflects the functional status of $\mathrm{p} 53$ protein $[25,26]$, the
$C D K N 1 A$ expression was measured and compared with that of $R A D 54 B$. This analysis was limited to samples without any p53 hotspot mutations observed in CRC because most of such p53 mutants lack the normal transcriptional activities [27, 28]. Using sequencing analysis of the p53 gene, 92 samples without p53 hotspot mutations were extracted from the combined training and validation set $(n=212)$. Our data showed that $C D K N 1 A$ expression tends to decrease remarkably in CRC samples which expression of $R A D 54 B$ are within an approximately 3 -fold increase compared with normal mucosa. Particularly, in samples with RAD54B expression values ranging between 1.00-2.95, Spearman's rank-order correlation demonstrated a significant weakly negative correlation between $C D K N 1 A$ and $R A D 54 B$ expression $(\rho$ $=-0.29, P=0.027$; Figure 3A).

The degradation of $\mathrm{p} 53$ caused by RAD54B requires the interaction between p53 and MDM2 [13]. A study reported that $\mathrm{p} 53$ has a sequence polymorphism resulting in either Pro or Arg at amino acid position 72, and that although both variants can equivalently transactivate $C D K N 1 A$, the $\operatorname{Arg} 72$ variant undergoes ubiquitination markedly better than the Pro72 variant via greater interaction with MDM2 [29]. Therefore we analyzed the sequence of amino acid position 72 and the correlation between $R A D 54 B$ and $C D K N 1 A$ expression. The analysis limited to 34 samples with Arg72 in 92 samples without p53 hotspot mutations revealed that there was a more remarkably significant negative correlation between $R A D 54 B$ and $C D K N 1 A$ expression provided $R A D 54 B$ expression values were under $6.00(\rho=-0.44, P=0.0099$; Figure 3B).
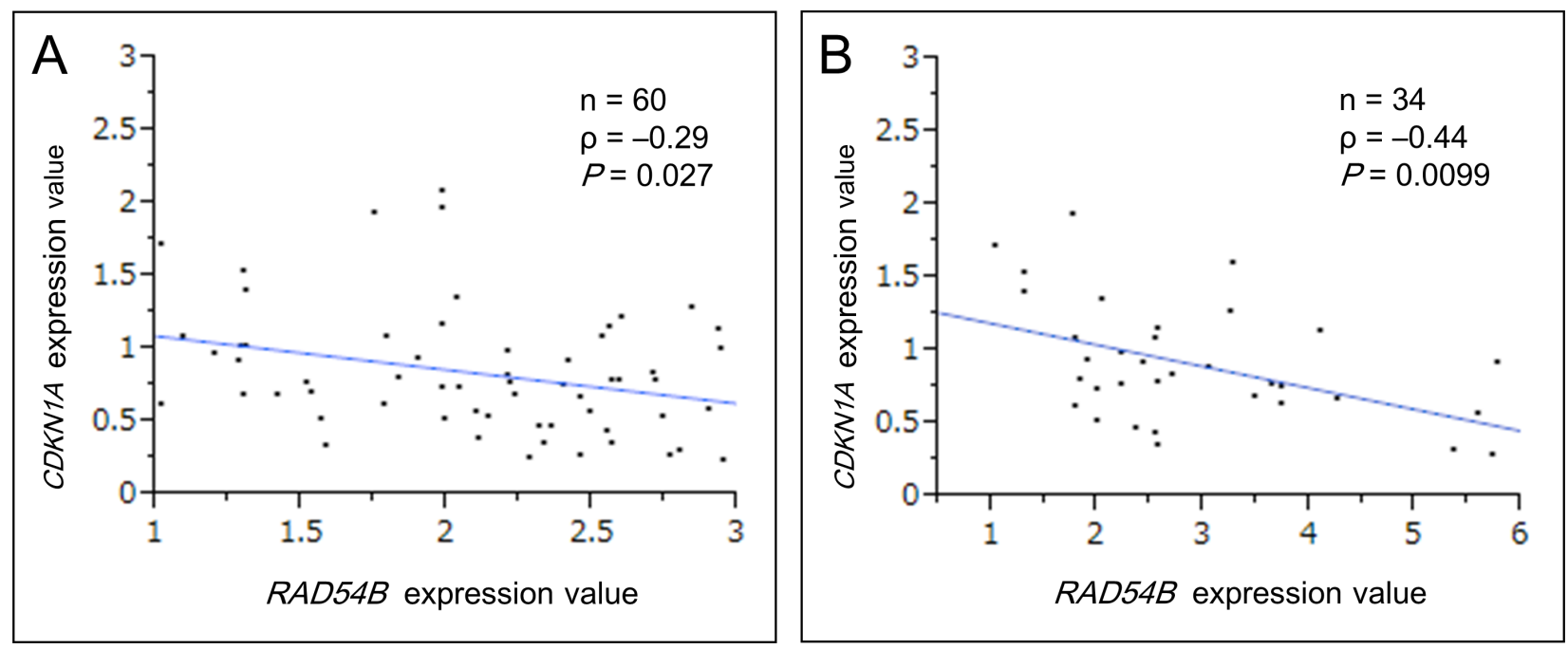

Figure 3: Scatter plot analysis between $R A D 54 B$ and $C D K N 1 A$ expression. A. A weakly significant negative correlation was found between $R A D 54 B$ and $C D K N 1 A$ expression values in wild-type p53 samples with $R A D 54 B$ expression values ranging between $1.00-2.95(\rho=-0.29, P=0.027)$. B. A moderately significant negative correlation was found between $R A D 54 B$ and $C D K N 1 A$ expression values in wild-type p53 samples with Arg72 variant, provided RAD54B expression values were under $6.00(\rho=-0.44, P=0.0099)$. 


\section{DISCUSSION}

The present study is the first report demonstrating the utility of $R A D 54 B$ as a prognostic biomarker in CRC patients. Human RAD54B was identified in 1999 as a homolog of RAD54. Biochemical studies have shown that RAD54B plays an important role in the DNA repairing system by HR [6-9]. However, few studies have focused on the clinical importance of RAD54B thus far. In this study, we confirmed that $R A D 54 B$ expression was elevated in the majority of the CRC tissues compared with corresponding normal mucosa (116/123 in the training set, 94.3\%). Based on this finding, we examined the impact of RAD54B expression on the clinical outcome of CRC patients. Our results revealed that CRC patients with high $R A D 54 B$ expression had significantly inferior DRFS compared with those with low RAD $54 B$ expression. Multivariate analyses using Cox proportional-hazards regression model demonstrated that high RAD 54B expression was an independent risk factor for distant recurrence in stage I-III CRC patients in both the training and validation sets. These results clearly demonstrate the prognostic value of $R A D 54 B$ expression in CRC patients.

We also analyzed RAD51 expression in the same training set. Although RAD51 is another central component in the HR pathway [15-18], the association of RAD51 expression and cancer prognosis remains controversial. Several studies reported that RAD51 overexpression was associated with poor prognosis in various cancers such as non-small-cell lung carcinoma, head cancers, esophageal squamous cell carcinoma, breast cancer, melanoma, and CRC [19-24]. In contrast, two studies targeting human glioblastoma and breast cancer reported the opposite results that high RAD51 expression was associated with better prognostic outcome [30, 31]. In our study, RAD51 expression was elevated in $60.2 \%$ (74/123 in the training set) of CRC samples compared with normal mucosa. This percentage was similar to previous studies [19-24]. However, RAD51 expression was not predictive of disease prognosis such as DRFS in our cohort. Our result implies that the prognostic ability of RAD 54B might be better than that of RAD51 in CRC patients. On the other hand, the discrepancy of our results compared with previous reports might arise from the difference in the analysis method, e.g., RAD51 expression was examined using immunohistochemistry in most previous studies, whereas we assessed RAD51 expression using a real-time PCR.

Meanwhile, the difference of clinical influence between $R A D 54 B$ and $R A D 51$ expression implies another pathway other than the HR, where RAD54B functions as a negative prognostic factor. Based on our in vitro study that RAD54B enhances p53 protein degradation via the MDM2-MDMX ubiquitin-ligase complex [13], we analyzed $C D K N 1 A$ expression, a target gene of $\mathrm{p} 53$, to elucidate the biological role of RAD54B in clinical CRC tissues. The analysis limited to CRC samples with $\operatorname{Arg} 72$ showed a significant inverse correlation between $R A D 54 B$ and $C D K N 1 A$ expression. This result partially supports the mechanism that RAD54B functions via the degradation of p53 protein function in clinical CRC tissues. However, we could not detect a significant correlation between $R A D 54 B$ and $C D K N 1 A$ expression in samples with remarkably high RAD54B expression, implying the presence of another unknown mechanism causing poor prognosis.

Several studies reported that RAD51 overexpression induced tumor resistance to ionizing radiation and anticancer drugs in vitro [32-34]. As for RAD54B, we previously found that xenografts derived from RAD54B knock out HCT116 cells grew more slowly than that from wild-type HCT116 cells after either oxaliplatin or 5-FU treatment in nude mice [13]. These results suggests the possibility that the effect of chemotherapy attenuates by RAD54B overexpression, and suggests the potential therapeutic target such as blocking the RAD54B overexpression to reinforce the effect of the chemotherapy. Unfortunately, in the present study, we were not able to prove statistically the association between $R A D 54 B$ expression and the effect of adjuvant chemotherapy consisting mainly of 5-FU based regimens probably because of our limited number of patients. We will further examine the effect of $R A D 54 B$ expression on chemotherapy by accumulating more $\mathrm{CRC}$ patients.

Limitations to the present study should be noted. First, the samples were obtained from a single institution and the sample size was not large enough for subgroup analysis. Second, the follow-up period may have been relatively short. Third, this was a retrospective study. A large, prospective cohort study would be desirable to determine the clinical usefulness of RAD54B more accurately.

In conclusion, this study is the first report clinically demonstrating the importance of $R A D 54 B$ as a prognostic biomarker in CRC patients. An increased expression level of $R A D 54 B$ may serve as an independent predictor of poor outcome in CRC patients treated with surgical resection, particularly for distant metastasis. Postoperative recurrence risk stratification by $R A D 54 B$ expression will be beneficial for more individual cancer strategies.

\section{MATERIALS AND METHODS}

\section{Collection of tissue samples and clinical data}

A total of 212 consecutive CRC samples were analyzed. All patients undergoing surgical resection were pathologically diagnosed with CRC at University of Tokyo Hospital, Tokyo, Japan. Samples obtained between 2008 and 2010 were included in the training set $(n=123)$, whereas those obtained between 2011 and 2012 were 
included in the validation set $(n=89)$. To prevent the influence of preoperative therapy on the targeted gene expression in resected specimens, patients receiving any preoperative chemotherapy or radiotherapy were excluded from the study.

A detailed database containing clinical and pathological information was provided for statistical analysis, and survival data were acquired from clinical charts. The cancer histological grade and clinical stage were identified in accordance with the 7 th edition of the TNM classification of Union for International Cancer Control (UICC). The study protocol was approved by the ethics committee of The University of Tokyo Hospital, and written informed consent was obtained from all participating patients.

\section{Total RNA extraction and cDNA synthesis}

Tumor tissue and corresponding normal mucosa were first immersed in RNAlater Tissue Protect Tubes (QIAGEN) overnight at $4^{\circ} \mathrm{C}$ and stored at $-20^{\circ} \mathrm{C}$ until analysis.

Total RNA was extracted from tissue samples using TRIzol Reagent (Life Technologies) and subsequently treated with DNase I (TAKARA BIO INC). Complementary DNA (cDNA) was synthesized from total RNA using PrimeScript RT Master Mix (TAKARA BIO INC) and used as a template for real-time PCR and cDNA sequencing. Each procedure was performed according to the manufacturer's instructions.

\section{Real-time PCR}

Gene expression of RAD54B, RAD51, CDKN1A, and TATA-binding protein $(T B P)$ were analyzed by realtime PCR using a 7500 Fast Real-Time PCR system (Life Technologies), with KAPA SYBR FAST qPCR Master Mix (KAPA Biosystems), according to the manufacturer's instructions. The following sets of primers were used: RAD 54B, 5'-TCCAGGTCTGAATGAAGAGATTAC-3' and 5'-TCTAGTACTTTCTTCACTAGGCAG-3'; RAD 51, 5'-TATCCAGGACATCACTGCCA-3' and 5'-GGTGAAGGAAAGGCCATGTA-3'; CDKN1A, 5'-GACTCTCAGGGTCGAAAACGG-3' and 5'-GCGGATTAGGGCTTCCTCTTG-3'; and TBP, 5'-TGCTGCGGTAATCATGAGGATA-3' and 5'-TGAAGTCCAAGAACTTAGCTGGAA-3'.

All measurements were performed in triplicates and mean cycle threshold $(\mathrm{Ct})$ values of both tumor tissue and corresponding normal mucosa were calculated for the expression analysis. Gene expression analysis was performed using the $\triangle \triangle \mathrm{Ct}$ method (RAD54B and RAD51) or the standard curve method $(C D K N 1 A)$ [35]. TBP was used as an internal control to normalize gene expression values for each gene expression analysis.
The $\Delta \mathrm{Ct}$ value represents the difference between the $\mathrm{Ct}$ value of the target gene (RAD54B and $R A D 51)$ and that of $T B P$ in the same sample, whereas the $\triangle \triangle \mathrm{Ct}$ value indicates the difference between the average $\Delta \mathrm{Ct}$ value of the tumor tissue and that of the corresponding normal mucosa. The targeted gene expression value was obtained as $2^{-\Delta \Delta C t}$ and used in the following analyses.

\section{cDNA sequencing of the p53 gene}

For sequencing of p53 gene transcripts, cDNA of the tumor tissue was amplified with PrimeSTAR HS DNA Polymerase (TAKARA BIO INC). Primer sets covering the regions from the first ATG to Gln167 and from Arg156 to Pro301 were used to detect the amino acid polymorphism at position 72 and CRC hot-spot mutations, respectively [29, 36]. Direct cDNA sequencing of each PCR product was performed using BigDye terminator v3.1 (Life Technologies) on a 3100 Genetic Analyzer (Life Technologies). The following sets of primers were used: ATG-Gln167, 5'-GTGACACGCTTCCCTGGAT-3' and 5'-CTCACAACCTCCGTCATGTG-3' and Arg156Pro301, 5'-GTGCAGCTGTGGGTTGATT-3' and 5'-CAGTGCTCGCTTAGTGCTCC-3'.

\section{Statistical analysis}

All statistical analyses were conducted using JMP pro version 10 software packages (SAS Institute). Continuous variables were presented as medians (interquartile ranges), and they were analyzed using KruskalWallis test (multiple groups) or Mann-Whitney U test (two groups). Categorical variables were presented as numbers (\%) and analyzed using Pearson's chi-squared test or Fisher's exact test, as appropriate. For measuring the strength of association between expression values of targeted genes, Spearman's rank-order correlation was used. Kaplan-Meier survival analysis was adopted for DRFS rate analysis, and survival differences between patients groups were evaluated using the log-rank test. DRFS was defined as the time from surgery to distant metastasis. Multivariable analyses for DRFS were performed using the Cox proportional-hazards regression model, and results were presented as hazard ratios with 95\% confidence intervals. Probability values $(P)<0.05$ were considered statistically significant.

\section{CONFLICTS OF INTEREST}

There are no conflicts of interest to declare.

\section{REFERENCES}

1. Brenner H, Kloor M and Pox CP. Colorectal cancer. Lancet. 2014; 383:1490-1502. 
2. Hoskins JM, Goldberg RM, Qu P, Ibrahim JG and McLeod HL. UGT1A1*28 genotype and irinotecan-induced neutropenia: dose matters. Journal of the J Natl Cancer Inst. 2007; 99:1290-1295.

3. Amado RG, Wolf M, Peeters M, Van Cutsem E, Siena S, Freeman DJ, Juan T, Sikorski R, Suggs S, Radinsky R, Patterson SD and Chang DD. Wild-type KRAS is required for panitumumab efficacy in patients with metastatic colorectal cancer. J Clin Oncol. 2008; 26:1626-1634.

4. Douillard JY, Oliner KS, Siena S, Tabernero J, Burkes R, Barugel M, Humblet Y, Bodoky G, Cunningham D, Jassem J, Rivera F, Kocakova I, Ruff P, et al. PanitumumabFOLFOX4 treatment and RAS mutations in colorectal cancer. N Eng J Med. 2013; 369:1023-1034.

5. Popat S, Hubner R and Houlston RS. Systematic review of microsatellite instability and colorectal cancer prognosis. J Clin Oncol. 2005; 23:609-618.

6. Hiramoto $\mathrm{T}$, Nakanishi $\mathrm{T}$, Sumiyoshi $\mathrm{T}$, Fukuda $\mathrm{T}$, Matsuura S, Tauchi H, Komatsu K, Shibasaki Y, Inui H, Watatani M, Yasutomi M, Sumii K, Kajiyama G, et al. Mutations of a novel human RAD54 homologue, RAD54B, in primary cancer. Oncogene. 1999; 18:3422-3426.

7. Miyagawa K, Tsuruga T, Kinomura A, Usui K, Katsura M, Tashiro S, Mishima H and Tanaka K. A role for RAD54B in homologous recombination in human cells. EMBO J. 2002; 21:175-180.

8. Sarai N, Kagawa W, Fujikawa N, Saito K, Hikiba J, Tanaka K, Miyagawa K, Kurumizaka H and Yokoyama S. Biochemical analysis of the N-terminal domain of human RAD54B. Nucleic Acids Res. 2008; 36:5441-5450.

9. Tanaka K, Kagawa W, Kinebuchi T, Kurumizaka H and Miyagawa K. Human Rad54B is a double-stranded DNAdependent ATPase and has biochemical properties different from its structural homolog in yeast, Tid1/Rdh54. Nucleic Acids Res. 2002; 30:1346-1353.

10. Helleday T. Homologous recombination in cancer development, treatment and development of drug resistance. Carcinogenesis. 2010; 31:955-960.

11. Krejci L, Altmannova V, Spirek $M$ and Zhao $X$. Homologous recombination and its regulation. Nucleic Acids Res. 2012; 40:5795-5818.

12. Thompson LH and Schild D. Homologous recombinational repair of DNA ensures mammalian chromosome stability. Mutat Res. 2001; 477:131-153.

13. Yasuhara T, Suzuki T, Katsura M and Miyagawa K. Rad54B serves as a scaffold in the DNA damage response that limits checkpoint strength. Nat Commun. 2014; 5:5426.

14. Grunda JM, Fiveash J, Palmer CA, Cantor A, FathallahShaykh HM, Nabors LB and Johnson MR. Rationally designed pharmacogenomic treatment using concurrent capecitabine and radiotherapy for glioblastoma; gene expression profiles associated with outcome. Clinl Cancer Res. 2010; 16:2890-2898.

15. Symington LS. Role of RAD52 epistasis group genes in homologous recombination and double-strand break repair. Microbiol Mol Biol Rev. 2002; 66:630-670.

16. Heyer WD, Li X, Rolfsmeier M and Zhang XP. Rad54: the Swiss Army knife of homologous recombination? Nucleic Acids Res. 2006; 34:4115-4125.

17. Ceballos SJ and Heyer WD. Functions of the Snf2/Swi2 family Rad54 motor protein in homologous recombination. Biochim Biophys Acta. 2011; 1809:509-523.

18. Benson FE, Baumann P and West SC. Synergistic actions of Rad51 and Rad52 in recombination and DNA repair. Nature. 1998; 391:401-404.

19. Qiao GB, Wu YL, Yang XN, Zhong WZ, Xie D, Guan XY, Fischer D, Kolberg HC, Kruger S and Stuerzbecher HW. High-level expression of Rad51 is an independent prognostic marker of survival in non-small-cell lung cancer patients. Br J Cancer. 2005; 93:137-143.

20. Connell PP, Jayathilaka K, Haraf DJ, Weichselbaum RR, Vokes EE and Lingen MW. Pilot study examining tumor expression of RAD51 and clinical outcomes in human head cancers. Int J Oncol. 2006; 28:1113-1119.

21. Li Y, Yu H, Luo RZ, Zhang Y, Zhang MF, Wang X and Jia WH. Elevated expression of Rad51 is correlated with decreased survival in resectable esophageal squamous cell carcinoma. J Surg Oncol. 2011; 104:617-622.

22. Tennstedt P, Fresow R, Simon R, Marx A, Terracciano L, Petersen C, Sauter G, Dikomey E and Borgmann K. RAD51 overexpression is a negative prognostic marker for colorectal adenocarcinoma. Int J Cancer. 2013; 132:21182126.

23. Barbano R, Copetti M, Perrone G, Pazienza V, Muscarella LA, Balsamo T, Storlazzi CT, Ripoli M, Rinaldi M, Valori VM, Latiano TP, Maiello E, Stanziale P, et al. High RAD51 mRNA expression characterize estrogen receptorpositive/progesteron receptor-negative breast cancer and is associated with patient's outcome. Int J Cancer. 2011; 129:536-545.

24. Jewell R, Conway C, Mitra A, Randerson-Moor J, Lobo S, Nsengimana J, Harland M, Marples M, Edward S, Cook M, Powell B, Boon A, de Kort F, et al. Patterns of expression of DNA repair genes and relapse from melanoma. Clinl Cancer Res. 2010; 16:5211-5221.

25. Cox LS. Multiple pathways control cell growth and transformation: overlapping and independent activities of p53 and p21Cip1/WAF1/Sdi1. J Pathol. 1997; 183:134-140.

26. Boulaire J, Fotedar A and Fotedar R. The functions of the cdk-cyclin kinase inhibitor p21WAF1. Pathol Biol. 2000; 48:190-202.

27. Pavletich NP, Chambers KA and Pabo CO. The DNAbinding domain of $\mathrm{p} 53$ contains the four conserved regions and the major mutation hot spots. Genes Dev. 1993; 7:25562564.

28. Kato S, Han SY, Liu W, Otsuka K, Shibata H, Kanamaru $\mathrm{R}$ and Ishioka $\mathrm{C}$. Understanding the function-structure and function-mutation relationships of p53 tumor suppressor 
protein by high-resolution missense mutation analysis. Proc Natl Acad Sci U S A. 2003; 100:8424-8429.

29. Dumont P, Leu JI, Della Pietra AC, 3rd, George DL and Murphy M. The codon 72 polymorphic variants of $\mathrm{p} 53$ have markedly different apoptotic potential. Nat Genet. 2003; 33:357-365.

30. Soderlund K, Skoog L, Fornander T and Askmalm MS. The BRCA1/BRCA2/Rad51 complex is a prognostic and predictive factor in early breast cancer. Radiother Oncol. 2007; 84:242-251.

31. Welsh JW, Ellsworth RK, Kumar R, Fjerstad K, Martinez J, Nagel RB, Eschbacher J and Stea B. Rad51 protein expression and survival in patients with glioblastoma multiforme. Int J Radiat Oncol Biol Phys. 2009; 74:12511255.

32. Vispe S, Cazaux C, Lesca C and Defais M. Overexpression of Rad51 protein stimulates homologous recombination and increases resistance of mammalian cells to ionizing radiation. Nucleic Acids Res. 1998; 26:2859-2864.

33. Slupianek A, Schmutte C, Tombline G, NieborowskaSkorska M, Hoser G, Nowicki MO, Pierce AJ, Fishel R and Skorski T. BCR/ABL regulates mammalian RecA homologs, resulting in drug resistance. Mol Cell. 2001; 8:795-806.

34. Hansen LT, Lundin C, Spang-Thomsen M, Petersen LN and Helleday T. The role of RAD51 in etoposide (VP16) resistance in small cell lung cancer. Int J Cancer. 2003; 105:472-479.

35. Livak KJ and Schmittgen TD. Analysis of relative gene expression data using real-time quantitative PCR and the 2(-Delta Delta C(T)) Method. Methods. 2001; 25:402-408.

36. Soussi T, Asselain B, Hamroun D, Kato S, Ishioka C, Claustres $M$ and Beroud C. Meta-analysis of the p53 mutation database for mutant p53 biological activity reveals a methodologic bias in mutation detection. Clin Cancer Res. 2006; 12:62-69. 